\title{
ASSESSING LABORATORY PROCEDURES FOR THE DECONTAMINATION OF POLAR SNOW OR ICE SAMPLES FOR THE ANALYSIS OF TOXIC METALS AND METALLOIDS
}

\author{
by \\ Claude F. Boutron and Françoise M. Batifol \\ (Laboratoire de Glaciologie et Géophysique de l'Environnement du C.N.R.S., B.P. 96, \\ 38402 St.-Martin-d'Hères Cedex, France)
}

\begin{abstract}
Most, if not all, Antarctic and Greenland snow and ice samples to be analyzed for toxic metals and metalloids such as $\mathrm{Pb}, \mathrm{Hg}, \mathrm{Sb}, \mathrm{Cd}, \mathrm{Ag}, \mathrm{Se}, \mathrm{As}, \mathrm{Cu}$ and $\mathrm{Zn}$ become more or less contaminated by these elements on their outsides, mainly during field collection. We assess here the various procedures which have been developed to try to decontaminate the samples. They include both mechanical and rinsing techniques. It appears that it is essential, but very difficult, to establish clearly the efficiency of these procedures. This can however be done by determining the geometry of contamination of the analyzed samples and by evaluating procedural blanks carefully. Such careful evaluation has been achieved at present only for mechanical procedures and for a few metals.
\end{abstract}

\section{INTRODUCTION}

At the present time, great efforts are being made to determine the occurrence of toxic metals and metalloids such as $\mathrm{Pb}, \mathrm{Hg}, \mathrm{Sb}, \mathrm{Cd}, \mathrm{Ag}, \mathrm{Se}, \mathrm{As}, \mathrm{Cu}$ and $\mathrm{Zn}$ in the stratified snow and ice deposited in the central areas of the Greenland and Antarctic ice sheets in order to obtain historical records of the atmospheric concentrations of these elements in the remote polar areas of both hemispheres (see, for instance, Murozumi and others 1969, Ng and Patterson 1981, Boutron 1982). Concentrations to be measured are unfortunately very low, in the range from $10^{-10}$ to $10^{-14} \mathrm{~g}$ $\mathrm{g}^{-1}$, so that it is extremely difficult to collect the samples in the field and to analyze them for toxic metals and metalloids in the laboratory without introducing an artifact contamination. Many published data are then erroneous by up to several orders of magnitude (Wolff and Peel 1985[b], Boutron in press).

In this paper, we shall assess critically the various procedures which have been developed in several laboratories in the attempt to remove contaminants from polar snow and ice samples intended for analysis for toxic metals and metalloids. This is a critical point since it appears that it is almost impossible to collect polar snow or ice samples in the field without introducing surface contamination for toxic metals and metalloids. The severity of this outside contamination varies greatly with the cleanliness of the field sampling procedures (Table I). It ranges from enormous contamination in deep ice cores thermally or electromechanically drilled in holes filled with a stabilizing fluid ( $\mathrm{Ng}$ and Patterson 1981) to very slight yet significant contamination in shallow samples collected from the walls of hand-dug pits by forcing acid-cleaned plastic tubes into the snow.

\section{MECHANICAL DECONTAMINATION TECHNIQUES}

2.1. Decontamination by chiselling veneers of snow or ice in progression from the outside to the inside of the sample

Patterson and his co-workers at the California Institute of Technology have developed a decontamination procedure suitable for both snow and ice samples. It involves the mechanical chiselling of veneers of snow or ice in sequence from the outside toward the centre of each sample. Each veneer subsample and the remaining inner sample are then analyzed separately. This procedure was developed initially for the analysis of highly contaminated, deep ice-core sections 10 to $12 \mathrm{~cm}$ in diameter, which were obtained by electromechanical drilling in a fluid-filled hole in Greenland (Hansen and Langway 1966) and by thermal drilling in a non-fluid-filled hole in Antarctica ( $\mathrm{Ng}$ and Patterson 1981). Later, the procedure described by $\mathrm{Ng}$ and Patterson was improved to allow the decontamination of slightly contaminated, shallow snow cores, $7.5 \mathrm{~cm}$ in diameter, which were obtained by hand drilling with an acid-cleaned polycarbonate auger in Antarctica (Boutron and Patterson 1983) and of moderately contaminated, large-size blocks of prehistoric surface blue ice collected at an Antarctic coastal ablation area (Boutron and Patterson 1983, Boutron and others 1984)

As an illustration, the improved procedure used for the shallow snow cores (Boutron and Patterson 1983) is as follows. All equipment and clothing used throughout is acid-cleaned. The snow-core sample is allowed to slide out of the plastic tube in which it was collected, and is then placed directly on a polyethylene sheet inside a cooled, double-walled, conventional polyethylene tray. This tray is located inside an ultra-clean laboratory flushed with filtered air (Patterson and Settle 1976). The operators wear, over their clean-room clothing, a large polyethylene bag and shoulder-length polyethylene gloves. The first veneer layer (about 0.5 to $1 \mathrm{~cm}$ thick) is then chiselled using a stainless-steel chisel by making successive shallow chord shavings from one end of the core section to the other along the side; the ends of the core are also shaved. The snow chips are allowed to fall directly into a specially designed quartz tray standing alongside the core. The shaved core is then transferred to a fresh clean part of the working area, and a second veneer layer is then removed similarly after putting on new acid-cleaned polyethylene gloves and cleaning the chisel and the quartz tray once again with ultrapure acids. The procedure is repeated until the remaining snow core is 3 to $4 \mathrm{~cm}$ in diameter.

It should be noted that several other investigators have tried to decontaminate snow or ice samples by mechanically removing the outside of their samples (see, for instance, Appelquist and others (1978) and Landy and Peel (1981)). However their procedures were unrefined and were much less carefully controlled: they probably did not avoid transfer, by entrainment, of surface contaminants towards the cleaner, inner layers.

\subsection{Direct subsampling using a sub-corer}

Wolff, Peel and their co-workers at the British Antarctic Survey have developed a mechanical subsampling procedure suitable for firn samples only. This procedure has been used for the decontamination of shallow firn cores hand-drilled with an aluminium drill in the Antarctic Peninsula and of surface snow samples collected directly 
TABLE I. ANTICIPATED CONTAMINATION FOR TOXIC METALS AND METALLOIDS IN POLAR SNOW AND ICE SAMPLES ACCORDING TO THE MAIN FIELD SAMPLING PROCEDURES USED
Type of sample
Expected contamination for
toxic metals and metalloids
Comments
References

I. RECENT SNOW

Direct collection in acid-cleaned plastic containers from pits

very small, however of ten significant

Hand-operated acidcleaned all-plastic auger

small, however of ten significant

medium

Hand-operated

aluminium auger

Conventional SIPRE- very high

type auger

II. ANCIENT ICE

Surface collection

in blue-ice coastal

areas

very small to medium

Thermal or electromechanical drilling in

a non-fluid-filled hole

very high mechanical drilling in

extremely high a fluid-filled hole highly dependent on Herron and others cleanliness of equip- (1977) ment

Boutron (1982)

highly dependent on Boutron and cleanliness of equip- Patterson (1983) ment

highly dependent on Peel and Wolff cleanliness of equip- (1982) ment and drill British Antarctic constitution Survey (1982)

Boutron (1979)

highly dependent on Murozumi and sampling procedure others (1969)

Boutron and others (1984)

penetration to centre Cragin and others of cores highly de- (1975) pendent on quality Herron and others of cores (1977)

Petit and others (1981)

penetration to centre $\mathrm{Ng}$ and Patterson of cores highly de- (1981) pendent on quality of cores into acrylic tubes (British Antarctic Survey 1982, Peel and Wolff 1982, Wolff and Peel 1985[a]).

The procedure (Wolff and Peel 1985[a]) can be summarized as follows. One end of the core sample is first discarded, either by cutting across the core using an arched teflon slicing tool, which is shaped so that the section to be subsampled is not touched by the tool, or by snapping the core whilst it straddles two pre-cleaned acrylic tubes. The core is then stood upright, and subsamples $(0.8$ to $3.7 \mathrm{~cm}$ in diameter) are taken at various distances from the centre of the core by pushing acid-cleaned, small-size teflon sub-corers vertically into the core using, if necessary, a polyethylene mallet. The procedure takes place inside a laminar-flow clean bench placed in a conventional cold room. The investigators wear acid-cleaned polyethylene gloves.

\subsection{Checking the integrity of the central parts of the} samples so obtained

It is absolutely fundamental to determine clearly whether the most central parts of the samples obtained by the procedures described in previous sections are free of contamination or not. Such contamination could have resulted either from diffusion of outside contamination during field sampling or sample storage or from entrainment and handling during the decontamination procedure itself. This evaluation can be done only from profiles showing, for each individual sample and each investigated metal or metalloid, the concentrations measured in successive veneers or subsamples as a function of distance from the centre of the sample.

For a given metal or metalloid, a continuous decrease with no plateau will indicate that exterior contamination has penetrated even to the centre of the sample so that the concentrations measured in the central part of the sample will give only an upper limit of the original concentration. On the other hand, if the concentration clearly levels off to a fixed value for several consecutive veneer layers or subsamples, this indicates that the concentration measured in this central part, after subtraction of procedural blanks, will provide the investigator with a reliable estimate of the original concentrations in Antarctic or Greenland snow and ice.

Figure 1 shows the measured concentrations of $\mathrm{Pb}$ in successive veneers from an ice-core section of age $5.5 \mathrm{ka}$ which was drilled electromechanically in a fluid-filled hole at Camp Century, Greenland and in an ice core section of age $2 \mathrm{ka}$ which was thermally drilled in a non-fluid-filled hole at Byrd station, Antarctica (Ng and Patterson 1981). Enormous $\mathrm{Pb}$ contamination is observed on the outside of the core in both cases. This outside value is however about one order of magnitude higher for the core obtained in a fluid-filled hole $\left(0.8 \times 10^{-6} \mathrm{~g} \mathrm{~Pb} \mathrm{~g}^{-1}\right)$ than for the one obtained in a non-fluid-filled hole $\left(0.3 \times 10^{-7} \mathrm{~g} \mathrm{~Pb} \mathrm{~g}^{-1}\right)$. An overall decrease of about $10^{6}$-fold and $10^{4}$-fold, respectively, is observed when going from the outside to the inside of these core sections. It is, however, impossible to determine from these curves whether the concentrations obtained for the central parts of the cores (1.6 and $2.2 \times 10^{-12} \mathrm{~g} \mathrm{~Pb} \mathrm{~g}^{-1}$, respectively) represent the original concentrations in the ice or not. This could have been determined only if the investigators had observed a plateau for several consecutive veneer layers in the central parts of the cores.

The same situation prevails for $\mathrm{Cd}, \mathrm{Zn}$ and $\mathrm{Cu}$ in a large size block $(37 \times 37 \times 37 \mathrm{~cm})$ of prehistoric blue ice 


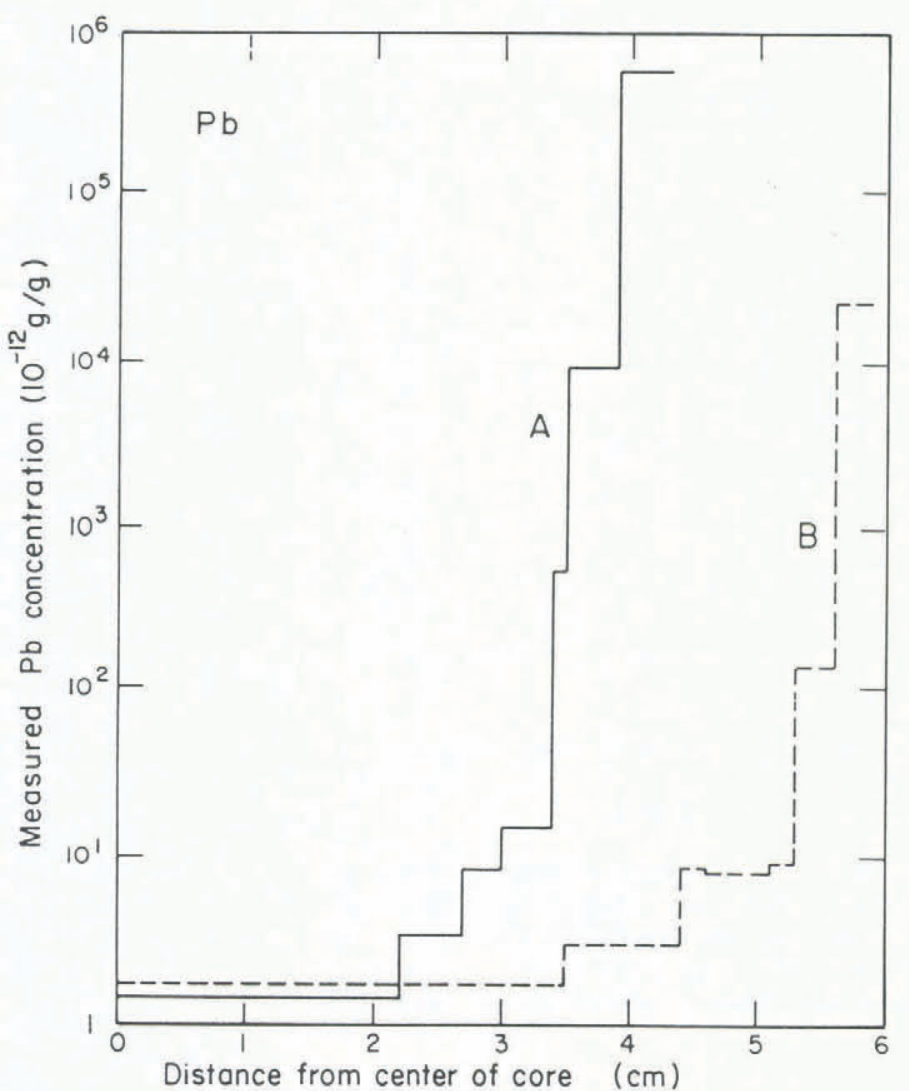

Fig.1. $\mathrm{Pb}$ concentrations as a function of radius in (A) an ice-core section, depth $949 \mathrm{~m}$ and age $5.5 \mathrm{ka}$, electromechanically drilled in a fluid-filled hole at Camp Century, Greenland, (B) an ice-core section, depth $342 \mathrm{~m}$ and age $2.01 \mathrm{ka}$, thermally drilled in a non-fluid hole at Byrd station, Antarctica. (From Ng and Patterson 1981.)

collected at an Antarctic coastal ablation site by Boutron and others (1984) (Fig.2). These investigators observed a sharp decrease in concentration of three metals when going from the outside to $12 \mathrm{~cm}$ from the centre of the block (2.6, 21.5 and $17.5 \times 10^{-12} \mathrm{~g} \mathrm{~g} \mathrm{~g}^{-1}$ for $\mathrm{Cd}, \mathrm{Cu}$ and $\mathrm{Zn}$, respectively). It is difficult, however, to evaluate clearly whether these values do represent the original concentrations in the Antarctic ice or not because the authors have analyzed only a single sample from the centre to $12 \mathrm{~cm}$ instead of analyzing several consecutive veneer samples.

Figure 3 shows the variations of the concentrations of $\mathrm{Pb}$ when going from the outside to the centres of two sections of a shallow snow-core which was hand-drilled using an acid-cleaned all-plastic auger at stake D 55 in East Antarctica (Boutron and Patterson 1983), and of one section of a snow core which was hand-drilled with an aluminium auger at Spaatz Island in the Antarctic Peninsula (British Antarctic Survey 1982). In the D55 core section from 8.56 to $8.68 \mathrm{~m}$ (Fig.3(A)), the decrease of concentrations is progressive, without any kind of plateau, which shows that outside $\mathrm{Pb}$ contamination has intruded in significant amounts to the centre of this sample. The rather high $\mathrm{Pb}$ concentration $\left(7.2 \times 10^{-12} \mathrm{~g} \mathrm{~Pb} \mathrm{~g}^{-1}\right)$ obtained for the central part of this sample is probably unreliable. For the D55 core section from 9.02 to $9.40 \mathrm{~m}$ (Fig.3(B)) and for the Spaatz Island core section (Fig.3(c)) the situation is radically different: a satisfying plateau of concentration is observed for several consecutive veneer layers or subsamples; it appears that no outside contamination has intruded to the centre of these samples, so that the concentration values observed in these central parts $\left(3.2\right.$ and $9 \times 10^{-12} \mathrm{~g} \mathrm{~Pb} \mathrm{~g}^{-1}$, respectively) will represent the original concentrations in the Antarctic snow providing procedural blanks are subtracted.

2.4. Evaluation of the contamination introduced by the decontamination procedure itself

Even if a clear plateau in the concentration profile is obtained across the central part of a given sample, this does not imply that the corresponding concentration value represents the original concentration of Antarctic or Greenland snow or ice. It is essential to assess the contamination introduced by the decontamination procedure itself and at each stage of the analytical process for each metal or metalloid and then to subtract this procedural blank from the plateau value.

To our knowledge, careful direct investigations of procedural blanks have been performed only by $\mathrm{Ng}$ and Patterson (1981) and by Boutron and Patterson (1983) in their $\mathrm{Pb}$ studies. To determine contamination introduced by $\mathrm{Pb}$ during their chiselling procedure (see section 2.1), these authors first performed careful analysis of the $\mathrm{Pb}$ content (about $0.2 \times 10^{-12} \mathrm{~g} \mathrm{~Pb} \mathrm{~g}^{-1}$ ) of the ultrapure water produced in the ultraclean laboratory at the California Institute of Technology. This water was then put in ultraclean polyethylene bottles, sealed, and frozen into a configuration
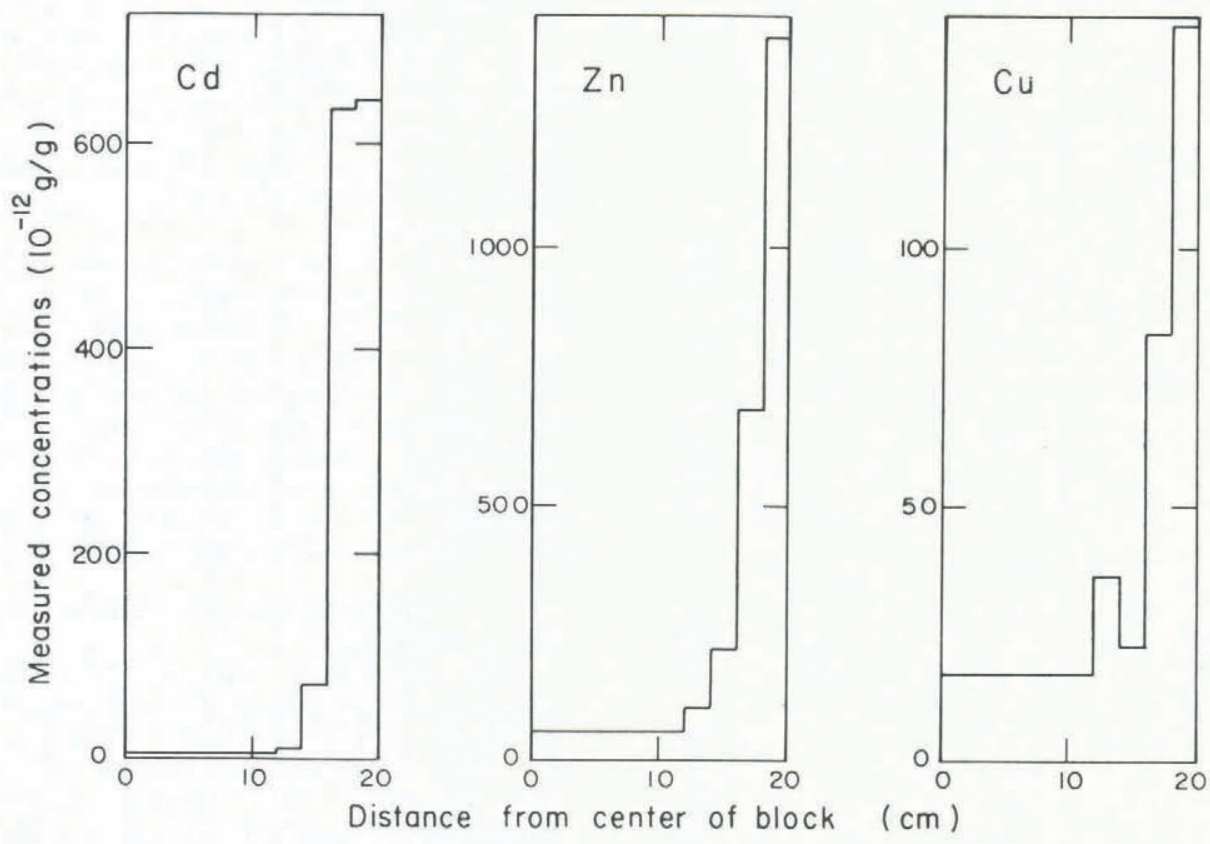

Fig.2. $\mathrm{Cd}, \mathrm{Zn}$ and $\mathrm{Cu}$ concentrations as a function of the distance from the centre of a cubic block of surface prehistoric blue ice more than $12 \mathrm{ka}$ in age collected in a coastal ablation area at Cap Prudhomme, Antarctica. (From Boutron and others 1984.) 


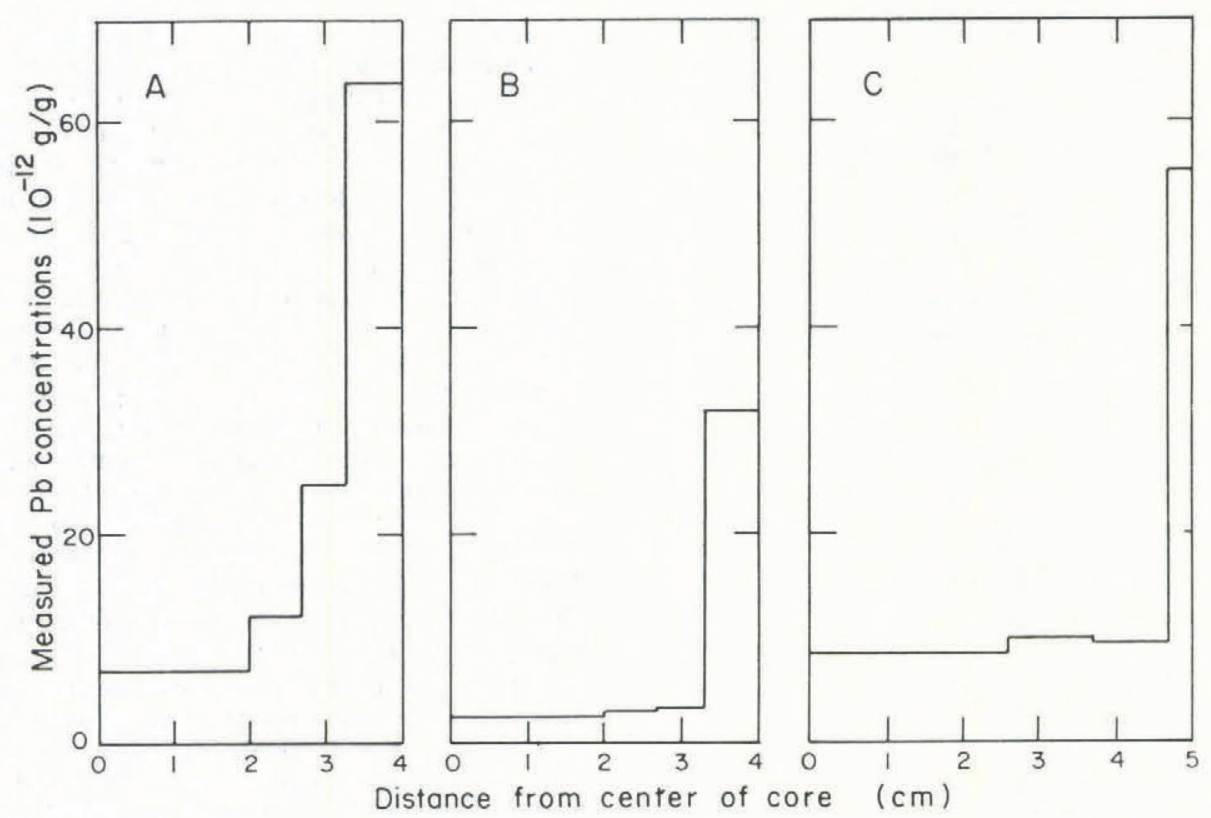

Fig.3. $\mathrm{Pb}$ concentrations as a function of radius in (A) a snow-core section collected at depth 8.56 to $8.68 \mathrm{~m}$ at stake D55, Antarctica, using an acid-cleaned all-plastic hand-operated auger, (b) a snow-core section collected at depth 9.02 to $9.40 \mathrm{~m}$ as above, (C) a snow core collected at depth 2.04 to $1.09 \mathrm{~m}$ at Spaatz Island, Antarctica, using a clean aluminium auger. ((A) and (B) are from Boutron and Patterson 1983, (C) from British Antarctic Survey 1982.)

similar to the Antarctic or Greenland cores. The bottles were cut using an acid-cleaned scalpel, and the artificial ice cores so obtained were chiselled according to the procedure described in section 2.1. The successive veneer layers and the remaining inner core were then analyzed for $\mathrm{Pb}$, knowing beforehand how much $\mathrm{Pb}$ was in the artificial ice. The chiselling procedure was found typically to introduce 50 to $400 \times 10^{-12} \mathrm{~g} \mathrm{~Pb}(\mathrm{Ng}$ and Patterson 1981, Boutron and Patterson 1983), i.e. about $30 \%$ of the $\mathrm{Pb}$ content of a typical Antarctic snow or ice sample.

These artificial samples were, of course, ice samples only. It seems indeed almost impossible to make artificial snow samples of known composition. As Boutron and Patterson were studying Antarctic snow cores, they had to make the implicit assumption that the procedural blank obtained using artificial ice samples gave a good estimate of the procedural blank for snow samples. This is a crucial point which will obviously need to be substantiated in the future.

\section{RINSING DECONTAMINATION TECHNIQUES}

\subsection{Description of the procedures}

These procedures can of course be used only for ice samples. They have been developed by Cragin, Herron, Langway and their co-workers for their numerous investigations of $\mathrm{Pb}, \mathrm{Cd}, \mathrm{Zn}, \mathrm{Cu}$ and other elements in various deep Greenland and Antarctic ice cores (Cragin and others 1975, Herron and others 1977, Herron unpublished). They were also used by LaViolette (unpublished) for his study of $\mathrm{Sb}, \mathrm{Sn}$ and other metals in a section of the deep ice core from Camp Century, Greenland, and by Petit and others (1981) for their study of $\mathrm{Zn}$ in the deep ice core from Dome C, Antarctica.

The procedure used by all these investigators is similar although there were slight variations dependent upon whether the drilling hole was filled with a fluid or not. For cores drilled without fluid, the procedure (Herron and others 1973, Langway and others 1974, Petit and others 1981) involves removing the surface outer layer of the ice-core section by running ultrapure water upon it inside a temperate clean room, until a given fraction (20 to $60 \%$ depending on the investigator) is removed. Upon completion of this rinsing, the remaining inner core only is analyzed. For cores obtained from fluid-filled holes, the procedure (Herron and others 1973, LaViolette unpublished) first involves several successive washings of the outer surface with acetone; it then follows the process described above for cores from non-fluid-filled holes.

\subsection{Checking the integrity of the central part of the samples so obtained}

It is necessary to assess clearly whether the central part of the ice samples so obtained are free of contamination or not. Very surprisingly, this has never been done for toxic metals and metalloids by the various investigators who used these rinsing procedures. To our knowledge, none of these investigators have studied the variations of the concentrations of toxic metals and metalloids in the remaining inner core as a function of the percentage of ice melted off. Such curves have been obtained only for $\mathrm{Na}$, $\mathrm{Mg}, \mathrm{K}$ and $\mathrm{Ca}$ by Ragone and Finelli (1972) and by Ragone and others (1972), and for $\mathrm{SO}_{4}, \mathrm{NO}_{3}, \mathrm{NH}_{4}, \mathrm{Cl}, \mathrm{Na}$ and $\mathrm{K}$ by Legrand and others (1984).

It is therefore impossible to evaluate the efficiency of these rinsing decontamination techniques, so that all data on toxic metals and metalloids obtained from the analysis of samples decontaminated in this way must be considered suspect. All these data will need to be validated in the future by careful investigation of the efficiency of the rinsing procedures.

For $\mathrm{Pb}$, however, there is now already clear evidence that the deep ice-core sections, which were decontaminated by means of the rinsing procedure of Cragin and others (1975), were still highly contaminated by up to one order of magnitude. This was convincingly demonstrated by $\mathrm{Ng}$ and Patterson (1981) who carefully studied the radial contamination characteristics of several Antarctic ice-core sections which were analogues of part of the sections of Greenland ice core studied by Cragin, Herron and co-workers (Herron and others 1977).

3.3. Evaluation of the contamination introduced by rinsing procedures

No investigator has so far tried to determine the contamination introduced for toxic metals and metalloids by rinsing procedures. This will obviously need to be done in the future by processing artificial ice-core sections made in the laboratory by freezing ultrapure water whose composition is accurately known.

\section{CONCLUSION}

It appears that much work still remains to be done in order to assess clearly the efficiency of the various 
decontamination procedures which have been developed for the analysis of toxic metals and metalloids in Antarctic and Greenland snow and ice samples. Both mechanical and rinsing procedures need to be fully assessed, but it is our feeling that the rinsing procedures will probably prove to be inefficient for toxic metals and metalloids, as already shown for $\mathrm{Pb}$. The main efforts should probably be devoted towards improving chiselling procedures or direct mechanical subsampling procedures, and evaluating their efficiency not only for $\mathrm{Pb}$, as already done by Patterson and co-workers, but also for the other toxic metals and metalloids.

Only when such a careful evaluation has been made will it be possible to obtain reliable data on the concentrations of toxic metals and metalloids in Antarctic and Greenland snow and ice. This will be a great achievement for then it will be possible to obtain reliable historical records for these elements in the remote polar areas of both hemispheres and to investigate their past natural cycles on a global scale.

\section{REFERENCES}

Appelquist $\mathrm{H}$, Jensen $\mathrm{K}$ O, Sevel $\mathrm{T}$, Hammer C 1978 Mercury in the Greenland ice sheet. Nature 273(5664): $657-659$

Boutron C 1979 Reduction of contamination problems in sampling of Antarctic snows for trace element analysis. Analytica Chimica Acta 106: 127-130

Boutron C 1982 Atmospheric trace metals in the snow layers deposited at the South Pole from 1928 to 1977. Atmospheric Environment 16(10): 2451-2459

Boutron C In press Atmospheric toxic metals and metalloids in the snow and ice layers deposited in Greenland and Antarctica from prehistoric times to present. In Davidson $\mathrm{C}$ I, Nriagu $\mathrm{J} O$ (eds) Toxic metals in the air. New York, Wiley (Advances in Environmental Science and Technology Series)

Boutron C, Patterson C C 1983 The occurrence of lead in Antarctic recent snow, firn deposited over the last two centuries and prehistoric ice. Geochimica et Cosmochimica Acta 47: 1355-1368

Boutron C, Leclerc M, Risler N In press Atmospheric trace elements in Antarctic prehistoric ice collected at a coastal ablation area. Atmospheric Environment 18(9): 1947-1953

British Antarctic Survey 1982 British Antarctic Survey Annual Report, 1981-82. Cambridge, British Antarctic Survey

Cragin J H, Herron M M, Langway C C Jr 1975 The chemistry of 700 years of precipitation at Dye 3, Greenland. CRREL Research Report 341

Hansen B L, Langway C C Jr 1966 Deep core drilling in ice and core analysis at Camp Century, Greenland, 1961-1966. Antarctic Journal of the United States 1(5): 207-208

Herron M M Unpublished The impact of volcanism on the chemical composition of Greenland ice sheet precipitation. ( $\mathrm{PhD}$ thesis, State University of New York at Buffalo, 1980)

Herron M M, Cragin J H, Langway C C Jr 1973 Improved procedures for the removal of surface contaminants from ice cores for chemical analysis. CRREL Technical Note

Herron M M, Langway C C Jr, Weiss $\mathrm{H} \mathrm{V}$, Cragin J H 1977 Atmospheric trace elements and sulphate in the Greenland ice sheet. Geochimica et Cosmochimica Acta 41(7): $915-920$

Landy M P, Peel D A 1981 Short term fluctuations in heavy metal concentrations in Antarctic snow. Nature 291(5811): $144-146$

Langway C C Jr, Herron M M, Cragin J H 1974 Chemical profile of the Ross Ice Shelf at Little America V, Antarctica. Journal of Glaciology 13(69): 431-435

LaViolette P A Unpublished Galactic explosions, cosmic dust invasions, and climatic change. Part I. (PhD thesis, Portland State University, 1983)

Legrand M, De Angelis M, Delmas R J 1984 Ion chromatographic determination of common ions at ultra trace levels in Antarctic snow and ice. Analytica Chimica Acta 156: 181-192
Murozumi M, Chow T J, Patterson C C 1969 Chemical concentrations of pollutant lead aerosols, terrestrial dusts and sea salts in Greenland and Antarctic snow strata. Geochimica et Cosmochimica Acta 33(10): 1247-1294

$\mathrm{Ng} \mathrm{A}$, Patterson C C 1981 Natural concentrations of lead in ancient Arctic and Antarctic ice. Geochimica et Cosmochimica Acta 45(11): 2109-2121

Patterson C C, Settle D M 1976 The reduction of orders of magnitude errors in lead analysis of biological materials and natural waters by evaluating and controlling the extent and sources of industrial lead contamination introduced during sample collection and analysis. In La Fleur P (ed) Accuracy in trace analysis. Washington, DC, National Bureau of Standards: 321-351 (Special Publication 42)

Peel D A, Wolff E W 1982 Recent variations in heavy metal concentrations in firn and air from the Antarctic Peninsula. Annals of Glaciology 3: 255-259

Petit J-R, Briat M, Royer A 1981 Ice age aerosol content from East Antarctic ice core samples and past wind strength. Nature 293(5831): 391-394

Ragone S E, Finelli R V 1972 Procedures for removing surface contaminants from deep ice cores. CRREL Special Report 167

Ragone S E, Finelli R V, Leung S, Wolf C 1972 Cationic analysis of the Camp Century, Greenland, ice core. CRREL Special Report 179

Wolff E W, Peel D A 1985[a] Closer to a true value for heavy metal concentrations in recent Antarctic snow by improved contamination control. Annals of Glaciology 7: 61-69

Wolff E W, Peel D A 1985[b] The record of global pollution in polar ice and snow. Nature 313(6003): $535-540$ 